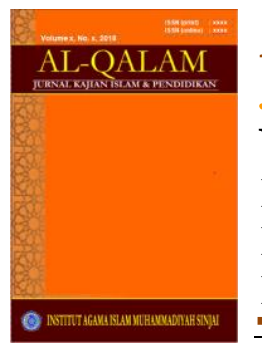

\title{
AL-QALAM
}

Jurnal Kajian Islam \& Pendidikan

Volume 06 No 022014

ISSN (print) : 1858-4152

ISSN (online) : -

Homepage : http://journal.iaimsinjai.ac.id/index.php/al-qalam

\section{TUJUAN PENDIDIKAN PERSPEKTIF HADIS NABI SAW}

\author{
Oleh: M. Zulkarnain Mubhar
}

$* * *$

\begin{abstract}
Abstrak
Education in the view of society is cultural inheritance from generation to generation, and the view of the individual is self-development potential and capabilities. Then, what about the purpose of education in the view of Prophetic traditions? to answer these questions, this paper attempted to study it using tahliliy method that begins with exploring the process takhrij al-hadith, hadith validity, analysis and understanding the text of hadith. The conclusion of hadith about the purpose of education has been narrated by al-Bukhariy, Muslim, Abu Dawud, al-Tirmidziy and Ibn Majah with a valid sanad. The Hadith is instructive that the filofosofis, education aims for people to get to know him so that it can perform tasks on earth Caliphate properly. Therefore, with the knowledge one can easily work righteousness that can easily also deliver them to heaven Allah.
\end{abstract}

Kata Kunci: Education, Hadith, Tahliliy, purpose.

\section{PENDAHULUAN}

endidikan dapat ditinjau dari dua segi: pertama, pendidikan dari sudut pandangan masyrakat. Pendidikan dengan sudut pandang ini berarti pewarisan kebudayaan dari generasi ke generasi yang bertujuan agar hidup masyarakat tetap berlanjut, atau dengan kata lain agar suatu masyarakat mempunyai nilai-nilai budaya yang senantiasa tersalurkan dari generasi ke generasi dan senantiasa terpelihara dan tetap eksis dari zaman ke zaman.; kedua, pendidikan dari sudut pandang individu. Pendidikan dengan sudut pandang ini berarti pengembangan potensi-potensi yang terpendam dan tersembunyi dalam diri setipa individu. Sebab, individu bagaikan lautan yang penuh dengan keindahan yang tidak tampak, itu karena terpendam di dasar laut yang paling dalam. Keindahan-keindahan yang terpendam tersebut perlu untuk ditampakkan ke permukaan laut sehingga dapat dirasakan dan disaksikan keberadaannya. Dalam diri setiap manusia memiliki pelbagai bakat dan kemampuan yang apabila dipergunakan dengan baik, maka akan berubah menjadi intan dan permata yang 


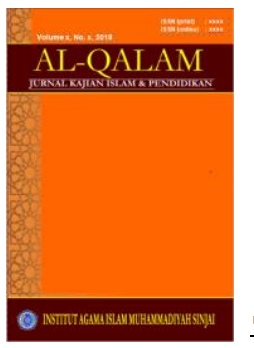

\section{AL-QALAM}

Jurnal Kajian Islam \& Pendidikan

Volume 06 No 022014

ISSN (print) : 1858-4152

ISSN (online) : -

Homepage : http://journal.iaimsinjai.ac.id/index.php/al-qalam

keindahannya dapat dinikmati oleh banyak orang dengan kata lain bahwa setiap individu yang terdidik akan bermanfaat bagi manusia lainnya. ${ }^{1}$

Dari kedua sudut pandang pendidikan di atas, kemudian datanglah Islam yang secara komprehensif memadukan kedua sisi bentuk pendidikan tersebut dengan berlandas pada petunjuk al-Qur'an dan al-Sunnah, dimana Islam mendidik individu menjadi manusia yang beriman, berakhlak mulia dan beradab yang kemudian melahirkan masyarakat yang bermartabat. Teori ini didasarkan pada firman Allah dalam QS. al-Taubah/9 : 122.:

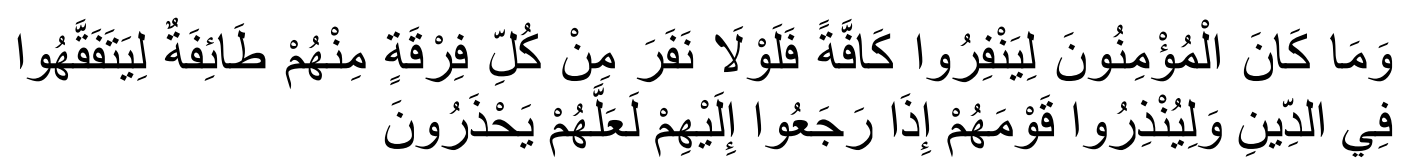

Terjemahnnya:

Tidak sepatutnya bagi mukminin itu pergi semuanya (ke medan perang).

Mengapa tidak pergi dari tiap-tiap golongan di antara mereka beberapa orang untuk memperdalam pengetahuan mereka tentang agama dan untuk memberi peringatan kepada kaumnya apabila mereka Telah kembali kepadanya, supaya mereka itu dapat menjaga dirinya.

Ayat di atas menunjukkan, tidaklah sepantasnya seluruh individu orangorang yang beriman (muslim) berangkat kemedan perang untuk memerangi kaum Kuffar dengan menggunakan senjata, akan tetapi hendaknya terdapat salah seorang diantar setiap golongan mencari pendidikan yang layak agar kembali kepada masyarakatnya dan mendidik mereka agar senantiasa menjaga diri mereka dan keluarga mereka dari jilatan api Neraka.

Selain itu Rasulullah Saw juga menegaskan bahwa setiap individu muslim baik pria maupun wanita berkewajiban mengenyam pendidikan yang layak dan baik, sebagaiman yang disabdakan oleh beliau Saw:

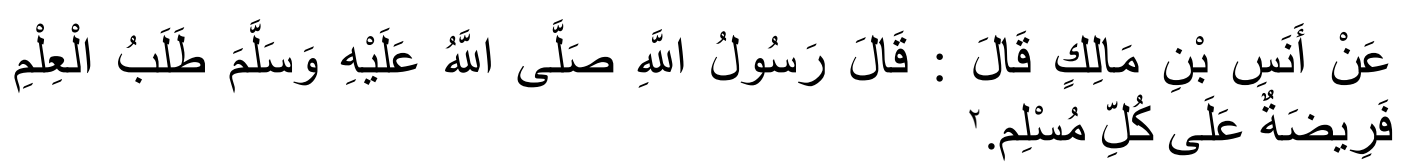

Artinya:

Dari Anas bin Malik beliau berkata: Rasulullah Saw bersabda: Menuntut ilmu adalah kewjiban bagi setiap individu muslim. (H.R Ibnu Majah) 3

${ }^{1}$ Hasan Langgulung, Asas-asas Pendidikan Islam, (Jakarta: Pustaka Al-Husna, 1987), h.

2 Muhammad bin Yazid al-Qazwiniy Ibn Majah, Sunan Ibn Mājah, vol. 1 (Bandung: Maktabah Dakhlan, T.Th), h. 81. 


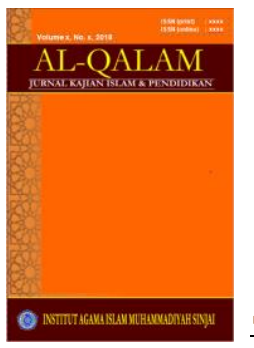

\section{AL-QALAM}

Jurnal Kajian Islam \& Pendidikan

Volume 06 No 022014

ISSN (print) : 1858-4152

ISSN (online) : -

Homepage : http://journal.iaimsinjai.ac.id/index.php/al-qalam

Berdasarkan tinjauan di atas, maka penulis dalam makalah ini berusaha untuk mengupas secara tahliliy kandungan matan suatu hadis yang berhubungan dengan tujuan pendidikan, yakni sabda Rasulullah Saw:

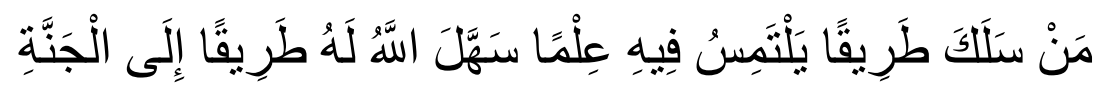

Artinya:

Barang siapa yang meniti jalan untuk mencaari ilmu, maka Allah memudahkan baginya jalan menuju surga.

Dari araian di atas, maka dapat dirumuskan beberapa masalah yang selanjutnya akan penulis bahas dalam pembahasan makalah ini, yaitu; Bagaimanakah kualitas sanad dan matan dari hadis tersebut ?; apa tujuan pendidikan yang terkandung pada hadis tersebut?.

\section{PEMBAHASAN}

\section{A. Takhrij al-Hadis}

Berdasarkan hasil penelusuran hadis melalui kitab al-Mu'jam al-

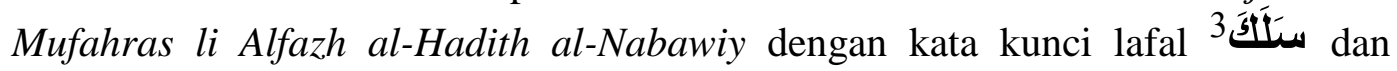
4َََسَ', ditemukan petunjuk bahwa hadis tentang tujuan pendidikan terdokumentasikan dalam beberapa kitab hadis, diantaranya: Al-Bukhary dalam Şąīh al-Jìmi' Kitab; al-'Ilm, Bab. Al-'Ilmu Qabla al-Qauli wa al-'Amali.; Muslim dalam Şą̄īh, Kitab; al-Żikr Bab; Fadhl al-Ijtimā' 'alā Tilāwat al-Qurān wa 'alā al-Żikr, No. Hadis; 38 (2699).; Abu Dawud, dalam Sunan Abū Dāwud,

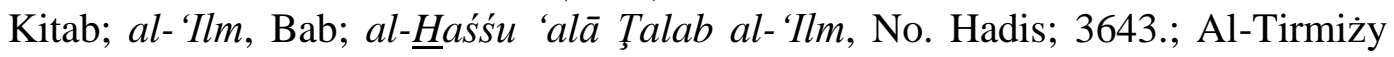
dalam Sunan, Kitab; al-'Ilm, Bab; Mã Jāa fì Fadhl al-Fiqh 'alā al-'Ibādah, No. Hadis; 2682, dan Kitab; al-Qirāāt, Bab; Mā Jāa anna al-Qur-ān Unżila 'alā Sab'at A $\underline{h r u f, ~ B a b ~ M i n h u, ~ N o . ~ H a d i s ; ~ 2945 . ; ~ d a n ~ I b n ~ M a ̄ j a h, ~ S u n a n, ~ M u q a d d i m a h, ~}$ Bab; Fadhl al-'Ilm wa al- $\underline{H}$ aśśu 'ala Ţalab al-'Ilm. No. Hadis; 223, dan 225.

\section{B. Susunan Sanad dan Matan Hadis}

Berdasarkan hasil temuan di atas, berikutnya penulis akan menyusun sanad dan matan hadis sesuai dengan urutan mukharrij, hal ini dilakukan untuk mempermudah proses studi terhadap sanad dan matan (redaksi) hadis. Pada

\footnotetext{
${ }^{3}$ A. J. Wensink, al-Mu'jam al-Mufahras li Alfäzh al-Hadīś al-Nabawìy, vol. 2 (Leiden: E. J. Brill, 1967), h. 506.

${ }^{4}$ Ibid., vol. 6, h. 147.
} 


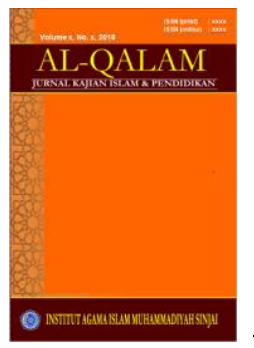

\section{AL-QALAM}

Jurnal Kajian Islam \& Pendidikan

Volume 06 No 022014

ISSN (print) : 1858-4152

ISSN (online) : -

Homepage : http://journal.iaimsinjai.ac.id/index.php/al-qalam

bagian lain matan hadis yang akan ditampilkan pada susunan sanad dan matan hadis hanyalah matan hadis yang sesuai dan semakna dengan matan hadis yang telah disebutkan pada bagian pendahuluan mengingat bahwa di antara redaksi hadis tersebut merupakan bagian dari hadis yang panjang (ahâadís al-ţiwâal). Berikut susunan sanad dan redaksi hadis;

1. Redaksi dari Şậ̄h $\underline{h}$ al-Jāmi’ karya al-Bukhāry

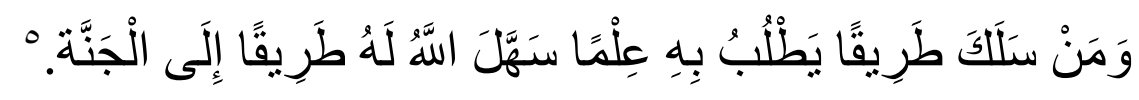

Artinya:

Dan barangsiapa yang meniti jalan untuk menuntut ilmu, maka Allah Swt akan memudhkan baginya jalan menuju surga.

2. Redaksi dari Şa $\underline{\operatorname{h}} \underline{\underline{h}}$ Muslim

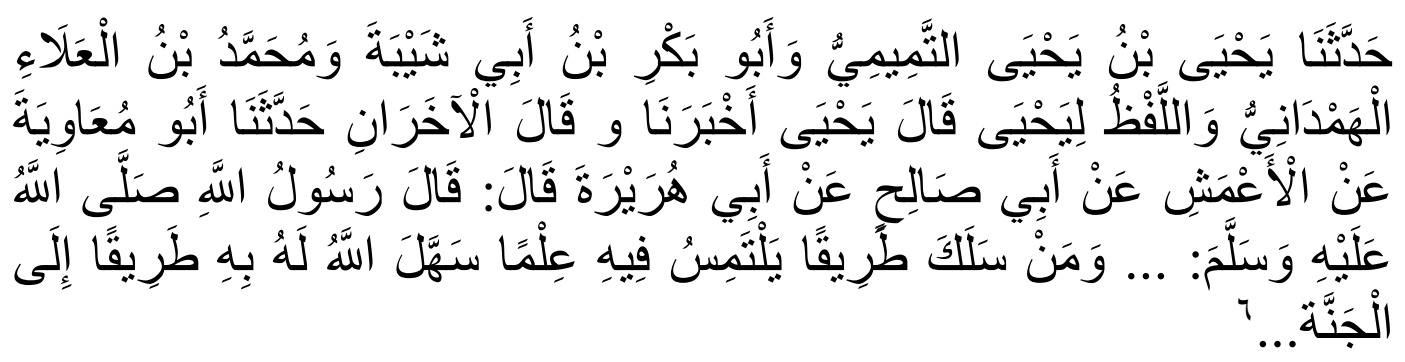

Artinya:

Telah disampaikan kepada kami oleh Yahya bin Yahya al-Tamīmy dan Abū Bakar bin Ab̄̄ Syaibah dan Muhammad bin al-'Alā al-Hamadāny dan lafadh milik Yahya, Yahya berkata telah diberitahukan kepada kami, dan dua lainnya (Ibn Abī Syaibah dan al-Hamadāny) berkata telah disampaikan kepada kami oleh Mu'āwiyah dari al-A'mash dari Abū Shālih, dari Abū Hurairah dia berkata: Rasulullah Saw bersabda: ....Barangsiapa yang meniti jalan untuk mendapatkan ilmu, Allah akan memudahan baginya jalan menuju surga...

\section{Redaksi dari Sunan Abū Dāwud}

5 Muhammad bin Isma'il al-Bukhariy, Şaḩīh al-Jāmi', vol. 1 (Kairo: Maktabah alSalafiyyah, 1400 H), h. 41

6 Muslim bin Hajjaj bin Muslim al-Qusyairiy al-Naisaburiy, Şah̄īh Muslim, vol. 4 (Kairo: Dar al-Hadits, 1412 H / 1991 M), h. 2074. 


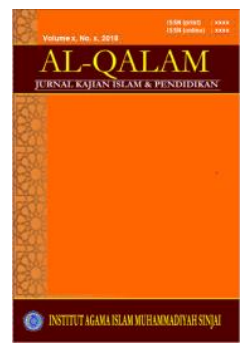

\section{AL-QALAM}

Volume 06 No 022014

ISSN (print) : 1858-4152

ISSN (online) : -

Homepage : http://journal.iaimsinjai.ac.id/index.php/al-qalam

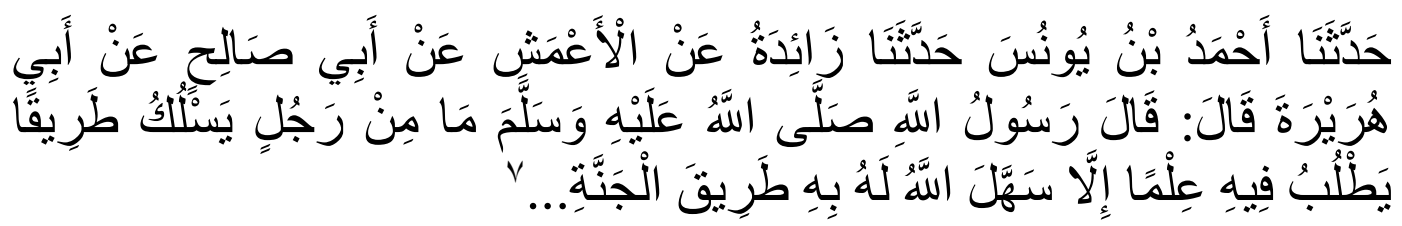

Artinya:

Telah disampaikan kepada kami oleh Ahmad bin Yūnus, telah disampaikan kepada kami oleh Zāidah dari al-A'masy dari Abū Shālih, dari Abū Hurairah dia berkata: Tidak sesorang yang meniti jalan untuk menuntut ilmu kecuali Allah Swt akan memudahkan baginya jalan menuju surga...

4. Redaksi dari Sunan al-Tirmidży

a. No. Hadis; 2945

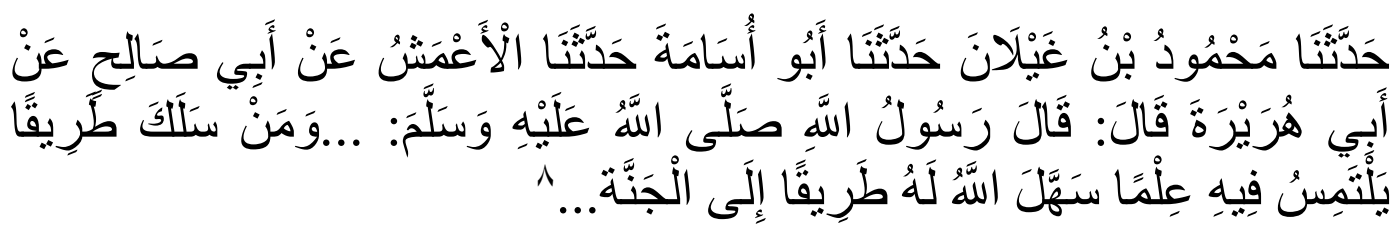

Artinya:

Telah disampaikan kepada kami oleh Mahmūd bin Ghaylān, Telah disampaikan kepada kami oleh Abū Usāmah, Telah disampaikan kepada kami oleh al-A'mash dari Abū Shālih, dari Abū Hurairah dia berkata: Rasulullah Saw bersabda: ....Barangsiapa yang meniti jalan untuk mendapatkan ilmu, Allah akan memudahan baginya jalan menuju surga...

b. No. Hadis; 2682.

\footnotetext{
7 Sulaiman bin al-Asy'ats al-Sijistaniy al-Azdiy, Sunan Abū Dāwud, vol. 4 (Beirut: Dar Ibn Hazm, 1418 H / 1997 M), h. 40.

${ }^{8} \mathrm{Abu}$ 'Isa Muhammad bin 'Isa al-Tirmidziy, Sunan al-Tirmidziy (Riyad: Maktabat alMa'arif, T.Th), h. 658.
} 

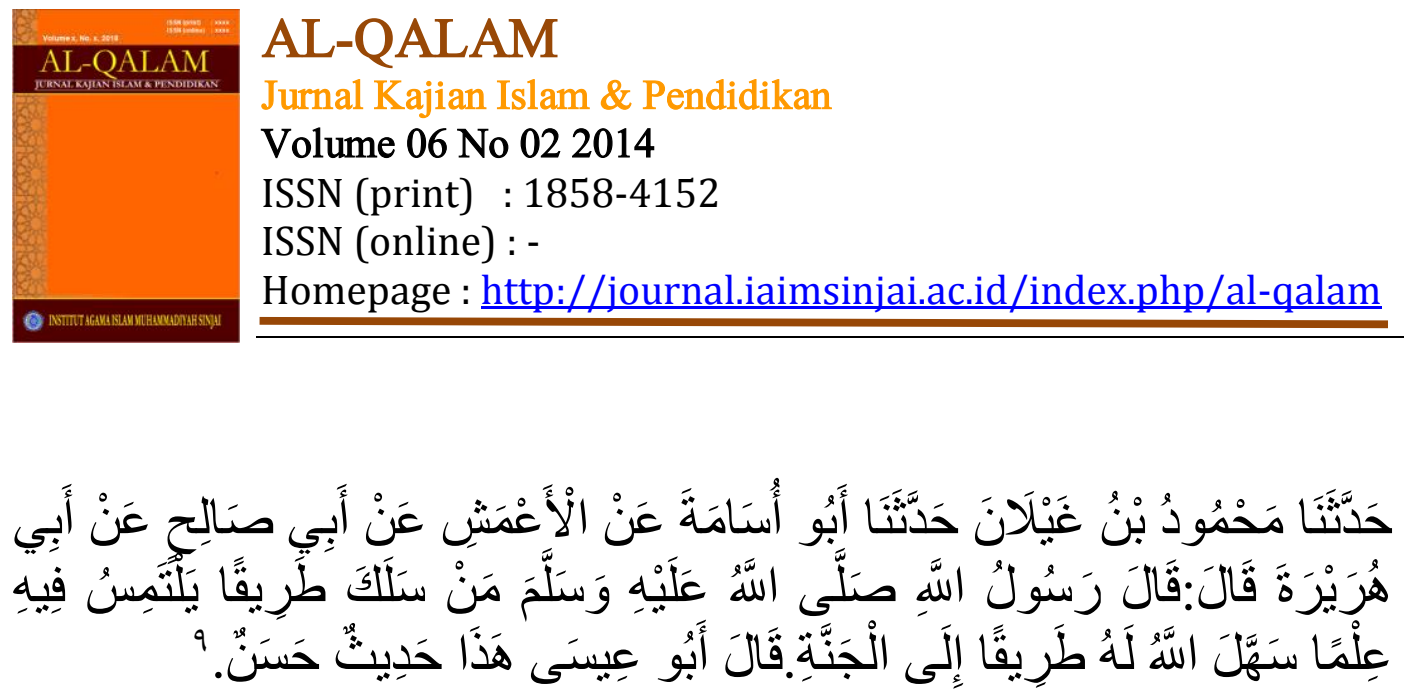

Artinya:

Telah disampaikan kepada kami oleh Mahmūd bin Ghaylān, Telah disampaikan kepada kami oleh Abū Usāmah, Telah disampaikan kepada kami oleh al-A'mash dari Abū Shālih, dari Abū Hurairah dia berkata: Rasulullah Saw bersabda: Barangsiapa yang meniti jalan untuk mendapatkan ilmu, Allah akan memudahan baginya jalan menuju surga.

\section{Redaksi dari Sunan Ibn Mājah}

a. No. Hadis; 223.

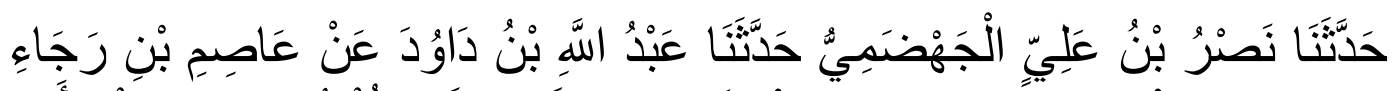

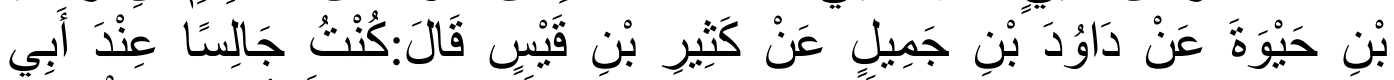

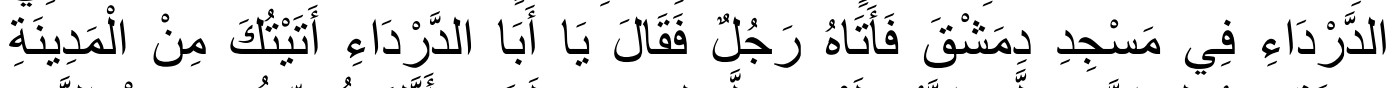

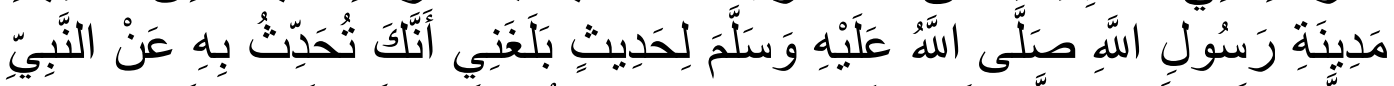

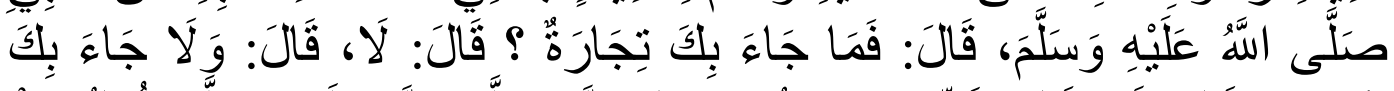

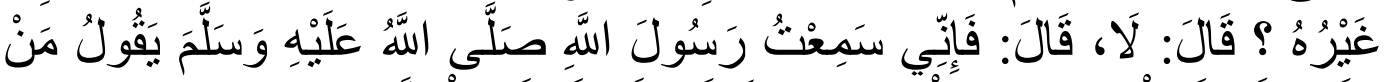

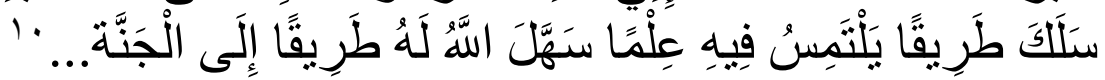

Artinya:

Telah disampaikan kepada kami oleh Nas\}r bin 'Aly al-Jahd \}amy, Telah disampaikan kepada kami oleh 'Abd Allāh bin Dāwud, dari 'Āshim bin Rajā' bin Haywah, dari Dāwud bin Jamīl, dari Kathīr bin Qays, dia berkata suatu ketika aku duduk bersama Abū al-Dardā' di Masjid Damaskus, Sesorang datang kepadanya dan berkata: 'wahai Abū alDardā' aku datang kepadamu dari Madinah kota Nabi Saw untuk (mendaptkan) sebuah hadis yang kamu dengarkan dari Rasulullah Saw', Abū al-Daradā' berkata : Jadi kamu datang bukan untuk berdagang? Orang itu menjawab: Bukan, Abū al-Dardā berkata: dan bukan pula selain itu ?, orang itu menjawab: bukan, Abu al-Dardā' berkata: Sesungguhnya kau pernah mendengar Rasulullah Saw bersabda:

${ }^{9}$ Ibid., h. 596.

10 Abu 'Abdillah Muhammad bin Yazid al-Qazwiniy Ibn Majah, Sunan Ibn Mājah (Riyad: Maktabah al-Ma'ārif, T.Th), h. 56. 


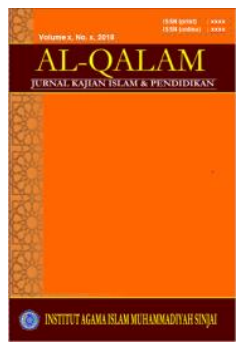

\section{AL-QALAM}

Jurnal Kajian Islam \& Pendidikan

Volume 06 No 022014

ISSN (print) : 1858-4152

ISSN (online) : -

Homepage : http://journal.iaimsinjai.ac.id/index.php/al-qalam

Barangsiapa yang meniti jalan untuk mendapatkan ilmu, Allah akan memudahan baginya jalan menuju surga...

b. No. Hadis; 225.

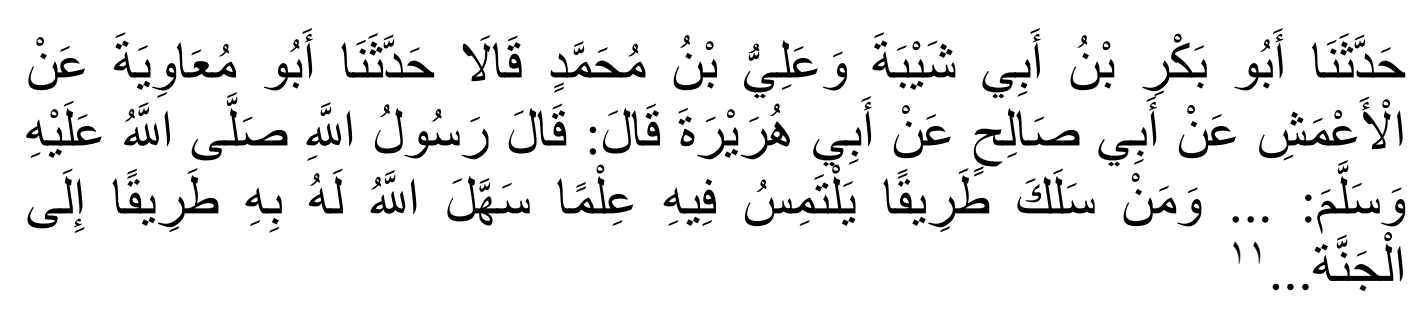

Artinya:

Telah disampaikan kepada kami oleh Abū Bakar bin Aby Shaibah dan 'Aly bin Muhammad keduanya berkata, Telah disampaikan kepada kami oleh Abū Mu'āwiyah, Telah disampaikan kepada kami oleh al-A'mash dari Abū Shālih, dari Abū Hurairah dia berkata: Rasulullah Saw bersabda: ....Barangsiapa yang meniti jalan untuk mendapatkan ilmu, Allah akan memudahan baginya jalan menuju surga...

\section{Studi Sanad Hadis}

Dari seluruh riwayat yang telah disebutkan terdahulu, tampak bahwa hadis yang dikaji mayoritasnya bermuara pada satu sahabat yakni Abū Hurairah dan satu kepada Abū al-Dardā', sementara riwayat al-Bukhary merupakan bagian dari riwayat yang mu'allaq (yakni riwayat tanpa sanad). Adapun sanad yang akan diteliti adalah sanad Ibn Mājah denga No. Hadis 223. Sebagai berikut:

Ibn Mājah: dia bernama lengkap Muhammad bin Yazīd al-Rub'y Abu 'Abd Allāh bin Mājah al-Qazwīny al-Hāaidz, pemilik karya al-Sunan dan memiliki banyak karya tulis dia mendengarkan dan mengambil hadis dari banyak guru di berbagai kota seperti Khurasān, 'Irāq, Hijāz, Mesir, Syām dan sebagainya diantara salah satu gurunya yang banyak tersebut adalah Naşr bin 'Alī alJahdhamī, dia lahir pada tahun $209 \mathrm{H}^{.}{ }^{12}$ dan wafat pada tahun $273 \mathrm{H}$ pada umur 97 tahun. $^{13}$

\footnotetext{
${ }^{11}$ Ibid., h. 67.

12 Jamaluddin Abu al-Hajjaj Yusuf al-Mizziy (654-742 H), Tahżib al-Kamāl fi Asmā' alRijāl, vol. 27 (Beirūt: Muassasah al-Risālah, 1413 H / 1992 H), h. 40.

13 Abu al-Falah 'Abd al-Hayyi bin Ahmad bin Muhammad al-'Ikriy, Syażarāt al-Żahab fi Akhbār man Żahab vol. 3 (Beirūt: Dār Ibn Kathīr, 1408 H / 1988 M), h. 208.
} 


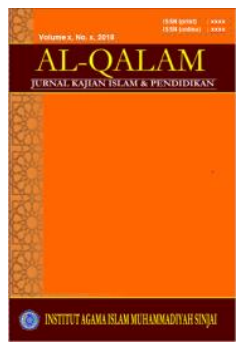

\section{AL-QALAM}

Jurnal Kajian Islam \& Pendidikan

Volume 06 No 022014

ISSN (print) : 1858-4152

ISSN (online) : -

Homepage : http://journal.iaimsinjai.ac.id/index.php/al-qalam

Naşr bin 'Aly al-Jahdhamy: dia bernama lengkap Nashr bin 'Aly bin Şubhān al-Azdy al-Jahdhamy Abū 'Amr al-Başry. Wafat tahun $250 \mathrm{H}$. Para kritikus hadis menilainya sebaggai periwayat yang şiqah. ${ }^{14}$

'Abdullāh bin Dāwud: dia bernama lengkap 'Abd Allah bin Dāwud bin 'Āmir al-Hamadāny Abū 'Abd al-Rahmān al-Kharīby al-Kūfy. Wafat tahun 213 H. Para ulama kritikus hadis menilainya sebagai periwayat yang şiqah dan seorang 'ābid (ahli ibadah), dia berhenti meriwayatkan hadis pada sisa umurnya.Imam al-Bukhāry tidak pernah menerima hadis darinya, menurut Ibn Hajar, al-Bukhāry pernah mendengarkan darinya ketika berada di kota Wāsith. ${ }^{15}$

'Āşim bin Rajā' bin Haywah al-Falasţīny. Para kritikus hadis menilainya sebagai periwayat yang şadūq, al-Dāruquthny menilainya sebagai periwayat yang dha'îf karena selalu meriwayatkan riwayat yang wahm (yang tidak jelas). ${ }^{16}$

Dāwud bin Jamīl, dia bernama Asli al-Walīd, Ibn Hajar dan alDāruquţny menilainya sebagai periwayat hadis yang dha'if karena ke-majhulannya (tidak dikenali kapasitas intelektualnya). ${ }^{17}$

Kaśīr bin Qays al-Syāmī, ada yang mengatakan bahwa namanya adalah Qays bin Kaśīr, tetapi Kaśīr bin Qays adalah yang lebih benar, Ibn Qāni' telah melakukan kesalahan dengan menempatkannya dalam deretan sahabat, Ibn Hajar dan al-Dāruqţny menilainya sebagai periwayat yang $\boldsymbol{d h} \boldsymbol{h}$ ' $\boldsymbol{\imath} \boldsymbol{f}$, meskipun Ibn Hibbān menyebutkannya dalam deretan periwayat yang şiqah $(a l$-şiqa $\bar{t}){ }^{18}$

Abū al-Dardā': dia bernama lengkap 'Uwaimir bin Zaid bin Qays alAnshāry, para ulama berbeda pendapat tentang nama ayahnya, sementara dia lebih dikenal dengan kunyah-nya yakni Abū al-Dardā', ada yang bependapat bahwa nama aslinya adalah 'Āmir, sementara 'Umair adalah laqab (panggilan). Dia adalah salah seorang sahabat Nabi Saw yang ikut pertama kali dalam perang Uhud, dia juga dikenal sebagai salah seorang sahabat yang 'äbid (ahli ibadah). Wafat pada tahun $32 \mathrm{H}$ tepatnya pada akhir masa pemerintahan khalifah 'Uśmān bin 'Affān dan hidup terakhir di kota Syām. ${ }^{19}$

Setelah melakukan studi terhadap seluruh individu periwayat hadis yang terdapat dalam susunan sanad Ibn Mājah sebagaiman yang termaktub dalam sunan-nya dengan No. Hadis; 223 baik dari sisi 'adālah (keadilan) maupun dhabt (kapasitas intelektual), tampak bahwa terdapat tiga orang periwayat dengan predikat dha 'īf (lemah) mereka adalah; 'Āşim bin Rajā' (periwayat 4), Dāwud bin

14 Ahmad bin 'Ali bin Hajar al-'Asqalaniy, Taqrib al-Tahżỉb (Beirut: Dar al-Kutub al‘Ilmiyyah, 1415 H /1994 M), 999.

15 Ibid., 503.

16 Ibid., 471.

17 Ibid., 305.

18 Ibid., 809.

19 Ibid., 759. 


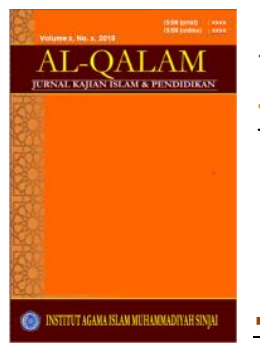

\section{AL-QALAM}

Jurnal Kajian Islam \& Pendidikan

Volume 06 No 022014

ISSN (print) : 1858-4152

ISSN (online) : -

Homepage : http://journal.iaimsinjai.ac.id/index.php/al-qalam

Jamīl (periwayat 5), dan Kaśīr bin Qays (periwayat 6). Dengan demikian dapat disimpulkan bahwa sanad Ibn Mājah tersebut adalah sanad yang dha'ț (lemah) disebabkan oleh lemahnya tiga periwayat dalam sanadnnya. Namun, jika seluruh sanad hadis dikumpulkan (i'tibār), maka sanad Ibn Mājah dapat terangkat derajatnya menjadi hasan li ghairihi karena adanya syāhid dari riwayat Abū Hurairah dan adanya mutabi' dari jalur sanad lainnya, terlebih lagi hadis tersebut diriwayatkan oleh Muslim dari para periwayat dengan derajat periwayatan tertinggi yakni śiqah śabt. Karena sanad hadis yang diteliti terangkat derajatnya dari dha'îf menjadi hasan li ghairihi, maka dapat dilakukan studi terhadap matan (redaksi) hadis.

\section{Studi Matan Hadis}

Bila studi terhadap hadis diarahkan kepada redaksinya, maka ditemukan adanya perbedaan lafadh dimana pada lafadh awal dari riwayat Abū Dāwud

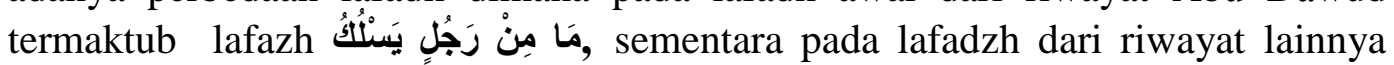
termasuk pada lafazh dari redaksi Ibn Mājah yang telah diteliti sanadnya menampilkan lafalzh مَنْ سَتَكَّ.

Pada bagian lain dari lafazh awal redaksi hadis dijumpai bahwa mayoritas redaksi diawali dengan huruf $9(w \bar{a} w u)$, huruf tersebut merupakan huruf antara (yakni huruf yang mengantarai dua kalimat atau kata), karena sesungguhnya redaksi hadis tersebut tergolong redaksi yang panjang. Adapun kelengkapan redaksi dari hadis tersebut adalah:

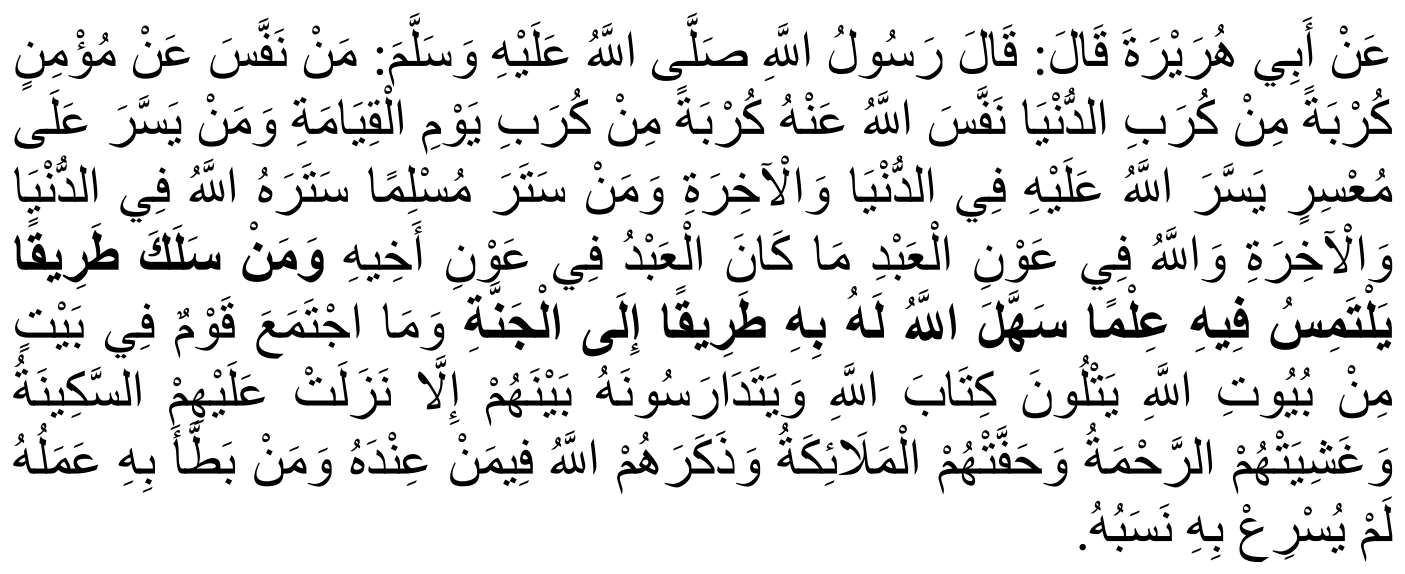

Redaksi hadis yang lengkap tersebut terdapat dalam riwayat Muslim dengan No. Hadis: 38 (2699), al-Tirmiży dengan No. Hadis: 2945, dan Ibn Mājah dengan No. Hadis: 225. Kemudian al-Tirmiży dengan No. Hadis; 2682 meringkasnya dengan mememulainya dari lafazh مَنْ سَتَكَّ dengan jalur sanad yang sama dengan miliknya sebagaimana yang terdapat pada hadis No. 2945. 


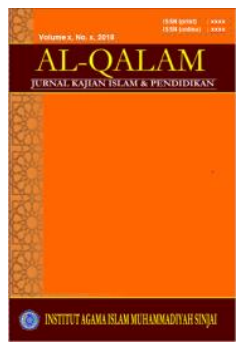

\section{AL-QALAM}

Jurnal Kajian Islam \& Pendidikan

Volume 06 No 022014

ISSN (print) : 1858-4152

ISSN (online) : -

Homepage : http://journal.iaimsinjai.ac.id/index.php/al-qalam

Adapun pada pertengahan lafazh, perbedaan terjadi antara lafazh dari riwayat selain Abū Dāwud dengan lafazh dari riwayat Abū Dāwud, dimana pada lafazh dari riwayat lain tidak mencantumkan kata إِلآ (kecuali). Kata tersebut tercantum dalam lafazh pada redaksi riwayat Abū Dāwud disebabkan kerena struktur redaskinya menggunakan lafadh al-nafyu (peniadaan) dan al-iśbāt (penetapan).

Berdasarkan analisis redaksional di atas, dapat disimpulkan bahwa dalam periwayatan redaksi dari hadis tentang tujuan pendidikan tersebut, telah terjadi proses periwayatan secara makna, dimana perkara tersebut tidak mempengaruhi validitas redaksi hadis selama tidak keluar dari makna dan ide pokok (mine idea) dari redaksi dan kandungan hadis.

Dari hasil studi baik sanad maupun matan di atas, disimpulkan bahwa hadis yang diteliti bila ditinjau dari sisi sanadnya adalah sanad dengan kualitas hasan li ghayrihi, sementara dari sisi matan atau redaksinya adalah hadis dengan kualitas śa $\underline{\boldsymbol{h}} \boldsymbol{\overline { h }} \underline{\mathrm{b}}$ baik lafazh maupun maknanya.

\section{E. Kandungan Hadis}

Hadis yang dikaji dalam tulisan ini, merupakan salah satu di antara sekian banyak hadis Rasulullah Saw. baik dalam bentuk qawliyyah, fi'liyyah, maupun taqririyyah tentang pendidikan, padahal beliau Saw sebagai seorang yang ummy (buta baca tulis) memiliki perhatian yang sangat besar terhadap ilmu dan pendidikan. Beliau mengangkat derajat dan sangat memuliakan para pemilik ilmu, kemudian beliau menerapkan nilai-nilai etika yang harus dipedomani oleh ilmuwan. Ini menunjukkan bagaimana sunnah Rasulullah Saw. telah terlebih dahulu menciptakan kaidah paling akurat dan nilai-nilai pendidikan paling agung, yang kebanyakan manusia -bahkan dari kalangan kaum muslimin sendiriberanggapan bahwa nilai-nilai pendidikan itu adalah hasil ciptaan alam modern yang dalam istilah Nashr Hamid Abu Zaid "intāj al-śāqafı̌y”- yang tidak diketahui kecuali oleh Barat. ${ }^{20}$

Pada hadis tersebut terkandung anjuran dan pahala yang sangat besar bagi mereka yang meniti jalan dalam mencari ilmu melalui berbagai media pendidikan, bahkan Rasulullah saw. memberikan garansi kemudahan mencapai surga bagi mereka yang meniti jalan ilmu.

Perintah meniti jalan-jalan pendidikan untuk mendapat ilmu juga disinggung oleh al-Qur'an, salah satunya disebutkan dalam QS. al-Taubah/9 : 122, Allah Swt berfirman:

20 Yusuf al-Qardhawiy, Sunnah, Ilmu Pengetahuan dan Peradaban, terj. Abad Badruzzaman (Yogya karta:Tiara Wacana, 2001), h. 192-193. 


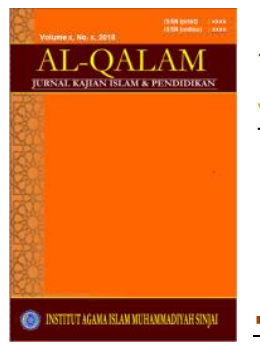

\section{AL-QALAM}

Jurnal Kajian Islam \& Pendidikan

Volume 06 No 022014

ISSN (print) : 1858-4152

ISSN (online) : -

Homepage : http://journal.iaimsinjai.ac.id/index.php/al-qalam

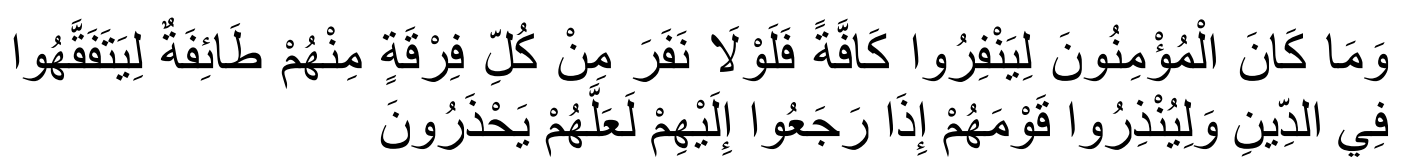

Terjemahnnya:

Tidak sepatutnya bagi mukminin itu pergi semuanya (ke medan perang). Mengapa tidak pergi dari tiap-tiap golongan di antara mereka beberapa orang untuk memperdalam pengetahuan mereka tentang agama dan untuk memberi peringatan kepada kaumnya apabila mereka telah kembali kepadanya, supaya mereka itu dapat menjaga dirinya.

Pada ayat di atas, Allah Swt memberikan penjelasan secara eksplisit tentang tujuan pendidikan, yakni agar dapat mengajarkan kepada kelompok masyarakat tempat mereka hidup dan bersosialisasi, nilai tujuan tersebut agar masyarakat dapat menjaga diri mereka baik secara individu maupun kelompok.

Tujuan pendidikan secara filosofis berdasarkan pemahaman dari ayat di atas maupun hadis Rasulullah Saw yang sedang dikaji, memberikan penjelasan bahwa manusia sejatinya adalah makhluk yang disempurnakan dengan akal oleh Allah Swt yang merupakan potensi dasar manusia, dengan potensi dasar tersebut manusia diharuskkan untuk menuntut ilmu melalui proses pendidikan. Oleh karena itu, tujuan meninti jalan ilmu pada hakikatnya adalah agar manusia dapat lebih mengenal dirinya dalam artian memanusiakan manusia, agar ia benar-benar mampu menjadi khalifah di muka bumi. ${ }^{21}$

Nilai penting lainnya dari memahami hadis di atas, bahwa dalam meniti jalan menuntut ilmu terdapat proses pendewasaan jasmani dan rohani, ${ }^{22}$ yakni bahwa selain tujuan filosofis, terdapat pula tujuan insidental yaitu meningkatkan kecerdasan motorik, emosional, intelektual dan spiritual, ${ }^{23}$ sebab dalam meniti jalan menuntut ilmu dibutuhkan ketenangan dan kesabaran dalam menghadapi berbagai kesulitan-kesulitan dalam belajar, Sebab kesuksesan seorang penuntut ilmu terletak dalam kesabarannya menghadapi berbagai bentuk kesulitan, kesusahan, dan keletihan dalam mengarungi proses pendidikan. Seluruh bentuk kesulitan yang dihadapi oleh penuntut ilmu merupakan proses pendewasaan jasmani dan rohani. Dalam al-Qur-ān Allah Swt mengisahkan tentang perjalanan Nabi Musa -'alaihi al-salam- bersama dengan pembantunya untuk mendapatkan ilmu dari Nabi Khidhr -'alaihi al-salam- sebagaimana yang diinformasikan dalam QS. Al-Kahfi/18: 60, Allah berfirman:

\footnotetext{
${ }^{21}$ Mastuhu, Menata Ulang Pemikiran Sistem Pendidikan Nasional Abad 21 (Yogyakarta: Safiria Insani Press, 2003), h. 136. 28.

${ }^{22}$ Sutari Imam Barnadib, Pengantar Ilmu Pendidikan (Yogyakarta: Andi Offset, 1993), h. ${ }^{23}$ Suharsono. Melejitkan IQ, IE E IS (Jakarta: Insani Press, 2001), h. 108.
} 


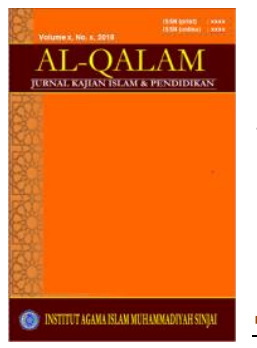

\section{AL-QALAM}

Jurnal Kajian Islam \& Pendidikan

Volume 06 No 022014

ISSN (print) : 1858-4152

ISSN (online) : -

Homepage : http://journal.iaimsinjai.ac.id/index.php/al-qalam

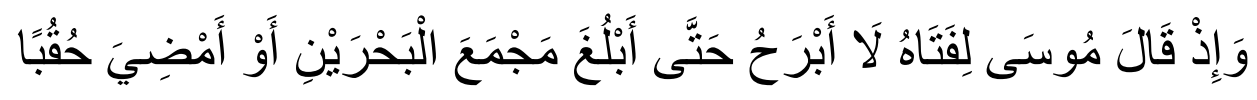

Terjemahannya:

Dan (Ingatlah) ketika Musa Berkata kepada muridnya: "Aku tidak akan berhenti (berjalan) sebelum sampai ke pertemuan dua buah lautan; atau Aku akan berjalan sampai bertahun-tahun".

Ayat di atas menjelaskan, betapa seorang Nabiyullah Musa - 'alihi alsalām- yang bergelar kalìm al-rahmān (teman dialog Allah Swt) terus berusaha meniti jalan dengan kesabaran menuju ilmu, hingga sampai ke tempat penididikan -pertemuan dua buah lautan - dimana beliau akan mendapatkan proses pendidikan lanjutan dari Allah Swt. melalui gurunya yang bernama Khidhr 'alaihi al-salām-.

Adapun tentang gambaran dimudahkannya seorang peniti jalan dalam menuntut ilmu menuju ke surga, al-Nawawy menjelaskan bahwa yang dimaksudkan dengan hal itu adalah hendaknya seseorang menyibukkan dirinya menuntut ilmu-ilmu yang disyari'atkan (al- 'ulum al-syar'îah) dengan syarat, dia menuntut ilmu hanya mengharap rida Allah Swt. Para ulama mempersyaratkan adanya niat yang ikhlas karena Allah Swt dalam menempuh proses pendidikan yang melelahkan sebab mayortitas manusia meremehkan keikhlasan dalam belajar utamanya para pemula. ${ }^{24}$ Sebab kemudahan meniti jalan ke surga bagi para peniti jalan menuntut ilmu diukur berdasarkan kadar keihlasannya dalam menjalani proses pendidikan yang melelahkan tersebut.

Dari uraian di atas dapat dipahami bahwa makna dari kata (thariqan) dan عِلَّْ ('ilman) dalam hadis tersebut adalah bahwa setiap manusia hendaknya memanfaatkan seluruh media pendidikan yang dapat membantu untuk mendapatkan ilmu utamanya ilmu agama secara bertahap dan berkesinambungan dengan tetap mengedepankan keikhlasan dan kesabaran dalam meniti proses pendidikan baik formal maupun non-formal, dan kemudahan meniti jalan menuju surga dapat dipahami bahwa ilmu dapat membantu memberika kemudahan dalam mengamalkan amal-amal saleh yang dapat dengan mudah pula menghantarkan menuju surga Allah Swt.

\section{KESIMPULAN}

Dari uraian di atas dapat disimpulkan bahwa tujuan pendidikan berdasarkan pemahaman hadis Nabi Saw yang dikaji secara filosofis adalah agar manusia dapat lebih mengenal dirinya dalam artian memanusiakan manusia

24 Yahya bin Syaraf al-Nawaiy, al-Minhaj Syarh Shahih Muslim bin al-Hajjaj, vol. 17 (Kairo: Mathba'ah al-Mishriyyah, 1349 H / 1930 M), h. 21. 


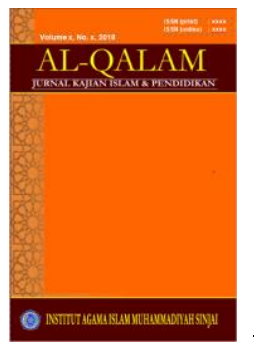

\section{AL-QALAM}

Jurnal Kajian Islam \& Pendidikan

Volume 06 No 022014

ISSN (print) : 1858-4152

ISSN (online) : -

Homepage : http://journal.iaimsinjai.ac.id/index.php/al-qalam

(humanity), agar ia benar-benar mampu menjalankan tugas kekhalifahan di muka bumi dengan baik dan benar sesuai dengan tuntunan Allah dan Rasul-Nya saw.

Adapun tujuan insidentalnya adalah untuk dapat meningkatkan kecerdasan motorik, emosional, intelektual dan spiritual yang diitandai dengan kedewasaan jasmani dan rohani.

Dalam pendidikaan, terjadi proses tahapan yang menuntut kesabaran dalam menghadapinya sehingga keikhlasan menjadi tuntutan utama sebagaimana yang telah dijelaskan oleh para ulama Islam.

Dengan ilmu seseorang dapat beramal saleh dengan mudah yang dapat dengan mudah pula menghantarkannya menuju surga Allah Swt.

\section{Wallāh A'lam}

\section{DAFTAR PUSTAKA}

Al-Qur-ān al-Karīm.

Abū Dāwud, Sulaimān bin al-Asy'aś al-Sijistāny al-Azdy. Sunan Abu Dāwud. Beirūt: Dār Ibn Hazm, 1418 H / 1997 M.

al-'Asqalāny, Aḥmad bin 'Aly bin Hajar. Taqrīb al-Tahż̄̄b. Beirut: Dar al-Kutub al-'Ilmiyyah, $1415 \mathrm{H} / 1994 \mathrm{M}$.

al-Bukhāriy, Muhammad bin Ismā'il. Şą̄inh al-Jāmi'. Kairo: Maktabah alSalafiyyah, $1400 \mathrm{H}$.

Barnadib, Sutari Imam. Pengantar Ilmu Pendidikan. Yogyakarta: Andi Offset, 1993.

Ibn Mājah, Abū 'Abdullāh Muhammad bin Yazīd al-Qazwīny. Sunan Ibn Mājah. Riyad: Maktabah al-Ma’ārif, T.Th. , Sunan Ibn Mājah. Bandung: Maktabah Dakhlan, t.th.

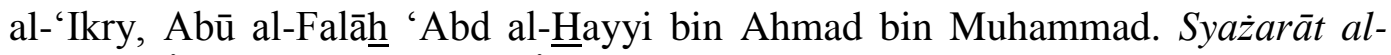
Żahab fì Akhb̄ār man Żahab. Beirūt: Dār Ibn Kathīr, 1408 H / 1988 M.

Langgulung, Hasan. Asas-asa Pendidikan Islam. Jakarta: Pustaka Al-Husna, 1987.

Mastuhu, Menata Ulang Pemikiran Sistem Pendidikan Nasional Abad 21. Yogyakarta: Safiria Insani Press, 2003. 
al-Mizziy, Jamāl al-Dīn Abū al-Hajjāj Yūsuf (654-742 H). Tahżīb al-Kamāl fì Asmā' al-Rijāl. Beirūt: Muassasah al-Risālah, 1413 H / 1992 H.

al-Nawawy, Yahya bin Sharaf. al-Minhaj Syarh Şah̄īh Muslim bin al-Hajjaj. Kairo: Mathba'ah al-Mishriyyah, 1349 H / 1930 M.

al-Qardhāwiy, Yūsuf. Sunnah, Ilmu Pengetahuan dan Peradaban. terj. Abad Badruzzaman. Yogya karta:Tiara Wacana, 2001.

al-Qusyairy, Muslim bin Hajjāj bin Muslim al-Naisābūry. Shahih Muslim. Kairo: Dār al-Hadīth, 1412 H / 1991 M.

Suharsono. Melejitkan IQ, IE \& IS. Jakarta: Insani Press, 2001.

al-Tirmiży, Abū 'Isā Muhammad bin 'Isā. Sunan al-Tirmidhy. Riyad: Maktabat al-Ma'ārif, t.th.

Wensink, A. J. al-Mu'jam al-Mufahrath li Alfazh al-Hadits al-Nabawiy. Leiden: E. J. Brill, 1967. 